\title{
Worldwide survey of education on tobacco in medical schools
}

\author{
Robyn L Richmond, Deborah S Debono, Donna Larcos, Linda Kehoe
}

\begin{abstract}
Objectives-To determine the extent of teaching about tobacco, tobacco-related diseases, and smoking cessation techniques in medical schools around the world; and to ascertain the problems of getting the teaching about tobacco onto the medical curriculum.

Design-Cross-sectional survey. Questionnaires were sent to the 1353 medical schools in 143 countries around the world using the World Health Organization's Directory of Medical Schools. The questionnaire was translated from English into French, Russian, Mandarin, and Japanese.
\end{abstract}

Subjects-Deans of medical schools worldwide, or their nominees.

Main outcome measures-Extent and format of teaching about tobacco in the medical curriculum, objectives and content of the courses on tobacco, and problems encountered in introducing the topic of tobacco.

Results-493 medical schools responded, representing $64 \%$ of countries and $36 \%$ of schools. Only $12 \%$ of medical schools did not cover the topic of tobacco in the medical curriculum. $58 \%$ of medical schools taught about tobacco during the teaching of other subjects. $40 \%$ taught tobacco by systematically integrating teaching with other modules. $11 \%$ had a specific module on tobacco. The medical schools reported on the objectives and content of their courses on tobacco, which commonly included knowledge about tobacco-related diseases and pharmacological issues. Only a third taught about smoking cessation techniques. $22 \%$ had encountered problems in introducing the topic of tobacco, and respondents offered solutions to overcome these problems.

Conclusions-Medical schools need continued encouragement to include tobacco issues in their curricula, with particular emphasis on teaching about smoking cessation techniques.

(Tobacco Control 1998;7:247-252)

School of Community Medicine, University of New South Wales, Kensington NSW 2052, Australia

R L Richmond

D S Debono

D Larcos

L Kehoe

Correspondence to: R Richmond

R.Richmond@unsw.edu.au smoking behaviour, attitudes and knowledge about tobacco and related diseases. ${ }^{1-4}$ This series of studies found differences in smoking prevalence among medical students in Europe, Asia, and Africa, and identified serious deficiencies in medical education on tobacco in regard to knowledge, attitudes, and behaviour, and recommended urgent changes in the medical curricula. This finding was supported by another study which reported that only a fifth of doctors thought that their education in medical school was adequate to assist them to advise smoking patients to stop. ${ }^{5}$

The next study in this series is to ascertain what students are taught about tobacco in medical schools. This endeavour is important as future doctors have an important role to play in controlling tobacco use among their smoking patients to contribute towards stemming the projected increase in smoking prevalence in the next century. ${ }^{6}$ The current study is a collaborative venture of the IUATLD and the World Health Organisation (WHO), Geneva.

The objectives of this study are: (a) to determine the extent of teaching about tobacco, tobacco-related diseases, and smoking cessation techniques to students in medical schools around the world; and (b) to ascertain the barriers to placing the teaching about tobacco onto the medical curriculum.

\section{Methods}

DESIGN AND SUBJECTS

In 1995 we conducted a cross-sectional survey using the WHO directory of medical schools. ${ }^{7}$ A questionnaire was sent to all medical schools listed, that is, 1353 schools in 143 countries around the world. Three mailouts were sent to the dean (or equivalent) of each medical school, including a reminder notice followed by a second questionnaire and cover letter. The covering letter instructed the dean or the dean's nominee to complete the survey on teaching about tobacco in their medical school, in conjunction with relevant personnel.

\section{QUESTIONNAIRE}

The questionnaire was developed for this study following a pilot trial in which medical schools worldwide were invited to a workshop which was part of the Global Conference on Lung Health, sponsored by the IUATLD and held in Mainz, Germany in 1994. Workshop participants submitted a poster which presented the status of teaching about tobacco and related diseases in their medical school according to preset guidelines established at the University of New South Wales, where the 
Table 1 Teaching about tobacco issues, by continent $(n=485)$

\begin{tabular}{lllll}
\hline & $\begin{array}{l}\text { Teaching a } \\
\text { specific module } \\
(\%)\end{array}$ & $\begin{array}{l}\text { Integrated } \\
\text { teaching (\%) }\end{array}$ & $\begin{array}{l}\text { No systematic } \\
\text { approach but } \\
\text { discussed (\%) }\end{array}$ & $\begin{array}{l}\text { Tobacco not } \\
\text { taught (\%) }\end{array}$ \\
\hline Africa & 10 & 45 & 35 & 24 \\
Asia & 8 & 34 & 54 & 24 \\
Australia/Pacific & 20 & 60 & 60 & 0 \\
Europe/ former Soviet Union & 11 & 37 & 61 & 0 \\
Middle East & 0 & 33 & 83 & 0 \\
North America & 14 & 53 & 62 & 9 \\
South America & 14 & 37 & 63 & 12 \\
Total & 11 & 40 & 58 & \\
\hline
\end{tabular}

content was analysed. The questionnaire used in this study incorporated these guidelines, including questions regarding country, region, size of student population, length of full-time study in medicine, the years in which tobacco and related diseases were predominantly taught about, the department responsible for teaching about tobacco-related topics, the objectives of the course, course content, range of teaching formats, teaching resources available, problems and barriers encountered in placing tobacco on to the medical curriculum, and possible solutions offered. Most questions included a selection of tick options with allowance for multiple responses and with space provided for any additional options. A few questions were left open ended (that is, solutions offered) and responses were grouped according to similarity at the time of analysis.

All medical schools received a questionnaire and covering letter in English. The questionnaire and the letter were also translated into four languages and distributed to medical schools where French, Russian, Japanese, and Mandarin is spoken. Translated questionnaires accompanied the questionnaire in English, and respondents chose which to complete. The process of translation included translation of the questionnaire into another language, and then back-translation into English by another person to check for accuracy.

\section{MAIN OUTCOME MEASURES}

The main areas covered in the survey were: extent and format of teaching about tobacco in the medical curriculum, objectives and content of the courses on tobacco, problems encountered in introducing the topic of tobacco onto the medical curriculum, and proposed solutions.

\section{Results}

RESPONSE RATES AND DEMOGRAPHICS

A total of 493 medical schools from 93 countries responded, representing a response rate of $36 \%$ of all medical schools and $64 \%$ of countries. Europe and the former Soviet Union had the highest response rate of $45 \%$, and the Middle East the lowest (28\%), with other geographical regions showing similar response rates (Africa, 36\%; Asia, 32\%; Australia/ Pacific, 36\%; North America, 36\%; and South America, 32\%). ${ }^{8}$ Countries were also classified according to whether they were developed or developing using the United Nations Human Development Reports ${ }^{9}$ and the State of the
World Population..$^{10}$ Responses were received from $48 \%$ of the medical schools in developed countries, and from $24 \%$ of schools in developing countries.

Surveyed medical schools varied widely in size of student population from fewer than 100 to greater than 6000 , with a majority $(67 \%)$ of schools having student numbers fewer than 1000. Developed countries tended to have smaller medical schools $(72 \%$ with student numbers fewer than 1000), whereas developing countries showed a more even distribution with $57 \%$ being small. Most medical schools required six years of full-time study for a medical degree, although some reported as few as three and as many as eight years of study.

TEACHING ABOUT TOBACCO

Table 1 presents the level of teaching about tobacco by region among the 485 (98\%) medical schools that answered this item. Note that respondents could give multiple responses to describe teaching about tobacco, where such teaching occurred. Most medical schools address the issues of tobacco and related diseases at some level, with only $12 \%$ of respondents indicating that the topic of tobacco was not covered anywhere in the curriculum. Respondents from the African and Asian regions were the most likely to indicate an absence of teaching about tobacco $(24 \%$ each), whereas such a response from other regions was rare or non-existent. Developed and developing countries were similar in this regard, with $11 \%$ and $14 \%$ of respondents, respectively, indicating no teaching about tobacco. Only $11 \%$ of respondents indicated the presence of a specific teaching module for tobacco issues. In fact, the most popular method of teaching about tobacco involved the non-systematic approach of discussing the topic during the teaching of other subjects $(58 \%)$. An alternative strategy reported by $40 \%$ of respondents was the systematic integration of teaching about tobacco with other related modules, covering areas such as the health effects, health education, smoking cessation, and tobacco policy. Many of the latter respondents offered both a systematic approach throughout the curriculum as well as non-systematic discussion about tobacco. Eight respondents reported use of all three methods to teach about tobacco.

The main departments responsible for teaching about tobacco were family/ community medicine and public health (41\%), and departments of pulmonary medicine (36\%). In most medical schools (65\%), more than one department was cited as responsible for teaching about tobacco. Such teaching occurred predominantly in years $3(41 \%)$ and $4(48 \%)$, although $9 \%$ of respondents stated that teaching about tobacco was included throughout the entire medical course. The most popular teaching formats were lectures (91\%), clinical attachments such as on hospital wards (57\%), tutorials (42\%), and special projects and presentations (37\%). Students were examined on their knowledge of tobacco and related diseases in their courses on clinical 
Table 2 Problems that have affected efforts to place the topic of tobacco and related diseases onto the medical curriculum, related to the level of country development

\begin{tabular}{llll}
\hline Problem & $\begin{array}{l}\text { Developed } \\
\text { country } \\
(n=54)\end{array}$ & $\begin{array}{l}\text { Developing } \\
\text { country } \\
(n=43) \%\end{array}$ & $\begin{array}{l}\text { Total } \\
(n=97) \%\end{array}$ \\
\hline Difficulty in motivating students & 72 & 65 & 69 \\
Lack of enthusiasm by staff & 74 & 49 & 63 \\
Administrative & 70 & 42 & 58 \\
Lack of sufficient knowledge and training & 44 & 70 & 56 \\
Government legislation & 63 & 44 & 55 \\
Tobacco is a major cash crop & 46 & 61 & 53 \\
Staff are smokers & 50 & 49 & 50 \\
Strong tobacco industry & 48 & 51 & 50 \\
More pressing diseases to deal with & 26 & 56 & 39 \\
Government changes frequently & 26 & 26 & 26 \\
Other & 4 & 12 & 7 \\
\hline
\end{tabular}

medicine $(65 \%)$, pathology $(47 \%)$, and in preventive medicine and public health (45\%).

OBJECTIVES OF THE COURSE ON TOBACCO

Respondents indicated the main objectives of their courses on tobacco, which were to impart knowledge of major tobacco-related diseases $(96 \%)$, to raise public awareness about the dangers of smoking and its impact on health $(76 \%)$, to give the students an understanding of the physical and psychological effects of nicotine addiction (73\%), to give recognition to the doctor's role in smoking cessation and prevention $(72 \%)$, to focus on prevention $(69 \%)$, and to inform students about smoking cessation techniques (34\%). Five per cent noted other objectives, including: to motivate students to become non-smoking role models, to inform them about the pressure of the tobacco industry in developing countries, to provide an example of cause and effect relationships, and to encourage research in this area.

COURSE CONTENT ON TOBACCO

Medical schools varied in the content of their teaching about tobacco. The most common areas in order of mention were: the major diseases related to tobacco use (98\%), pharmacological issues and the harmful components of tobacco smoke $(71 \%)$, the effects of passive smoking $(68 \%)$, the psychological and physical addiction associated with tobacco (64\%), smoking cessation techniques including those delivered by doctors (39\%), and adolescent smoking $(30 \%)$. Course content was similar in developed and developing countries, although medical schools in developed countries were more likely to teach smoking cessation techniques than those in developing countries ( $44 \%$ vs $28 \%$ ). There was also a tendency for respondents in developed countries compared with developing countries to discuss the psychology of addiction ( $70 \%$ vs $53 \%$ ).

PROBLEMS ENCOUNTERED

Among those medical schools that taught about tobacco, $22 \%$ reported moderate to severe problems in introducing the topic of tobacco and related diseases onto the medical curriculum. Table 2 provides a summary of the problems ticked, to be viewed qualitatively due to the relatively small number of responses. The most commonly ticked problems were difficulty in motivating students and lack of enthusiasm among staff. Indeed, half of these medical schools reported having smokers on staff, which was viewed as a barrier to introducing a teaching programme about tobacco. Other major problems listed in table 2 , in order of mention, were: administrative problems which included lack of cooperation and coordination between departments in medicine and the need for curriculum development; lack of knowledge and training in teaching about tobacco-related diseases and cessation techniques; lack of government legislation restricting smoking in public places and a reticence to put a levy on tobacco; and tobacco's status as the country's major cash crop, so that the government is not pro-active in tobacco control. This latter point was exacerbated in some countries where the tobacco industry was strong. Additional problems were: the need to deal with more pressing and immediate diseases and natural disasters. Some complained about constant changes in government and its policies, which made changes in the area of tobacco control and education difficult. Schools in developed countries tended to complain more about administrative difficulties, staff and student apathy, and lack of government legislation, while schools in developing countries were concerned about the lack of staff training, the fact that tobacco was a cash crop for their country or region, and that there were more pressing diseases to worry about. Some respondents noted other problems including an already crowded curriculum, a lack of medical education policy, pressure from foreign advertisements, and a culture in which smoking is a normal part of social intercourse.

SOLUTIONS TO PROBLEMS

Respondents from 71 medical schools offered possible solutions to the problems they have encountered, which were broadly grouped under the seven headings shown in table 3. Improvements in administration methods were mentioned most frequently, and included comments regarding additional funding required, revision of course content and teaching methods, and the need for integration and cooperation between various departments. The need to change attitudes about tobacco was noted at all levels, within the medical schools among staff and students, and externally within the community and at the governmental level. Improvement in community awareness was stressed by some respondents, who felt this was hampered by poor communication and conflicting interests. Other respondents felt little progress would be made at any level unless government attitudes and legislation changed. There was particular emphasis on legislation to control advertising and the need to find an alternative to tobacco as the major cash crop. Respondents from developing countries were less likely to cite administrative solutions than those from developed countries, but more likely to cite the need for resources and training and a need for changes in attitudes at the government and community levels. 
Table 3 Solutions offered to the problem of getting the topic of tobacco and related diseases onto the medical curriculum

\begin{tabular}{llll}
\hline Solution offered for improvement of: & $\begin{array}{l}\text { Developed country } \\
(n=34) \%\end{array}$ & $\begin{array}{l}\text { Developing country } \\
(n=37) \%\end{array}$ & $\begin{array}{l}\text { Total } \\
(n=71) \%\end{array}$ \\
\hline Administration & 50 & 35 & 42 \\
Staff attitudes & 32 & 24 & 28 \\
Government attitudes & 17 & 30 & 28 \\
Community awareness & 15 & 32 & 24 \\
Resources and training & 9 & 30 & 20 \\
Student attitudes & 9 & 8 & 9 \\
Other & 3 & 3 & 3 \\
\hline
\end{tabular}

Respondents who reported no teaching about tobacco on the curriculum were asked further questions about past and future inclusion of the topic. Among these 58 respondents, $40(69 \%)$ indicated that tobaccorelated issues had never been taught, $17(29 \%)$ had taught about tobacco in the past, and 17 $(29 \%)$ indicated that they were in the process of including tobacco issues in the curriculum.

The Tobacco Prevention Section of the IUATLD has produced a book called Educating medical students about tobacco: planning and implementation, ${ }^{11}$ with contributions from medical schools around the globe. Ninety-seven per cent of medical schools indicated an interest in obtaining a copy.

\section{Discussion}

TEACHING ABOUT TOBACCO

This survey of the world's medical schools has shown that an encouraging majority of those who responded have some teaching on tobacco issues, with the most popular method being non-systematic discussion during the teaching of other subjects. Many schools reported systematic integration of teaching about tobacco with other subjects; however, only one in 10 had a specific module on tobacco in the medical curriculum.

Although medical schools from developing countries tended to report an absence of teaching about tobacco more frequently than developed countries ( $14 \%$ vs $11 \%$ ), and were a little less likely to report having a specific module for tobacco issues ( $8 \%$ vs $12 \%$ ), this by no means draws a sharp distinction between the groups on which future initiatives can be based. Developing and developed countries require attention. All 58 schools that reported no teaching about tobacco were situated in Africa, Asia, Europe, or South America. And yet, of the 52 schools that reported having a specific module for tobacco, all regions were represented except the Middle East. It would appear that the presence or absence of teaching about tobacco may not be strictly related to stage of the country's economic development, but to more idiosyncratic and individual characteristics of the medical school. It may also be related to internal factors, such as attitudes of the staff towards smoking, or lack of administrative support for teaching, or to external issues, such as cultural, governmental, or economic imperatives.

Such results suggest that medical schools need continued encouragement to include tobacco issues in their curricula, not just the $12 \%$ that do not cover the topic at all, but also those that cover the topic less systematically.
Adoption of a specific module about tobacco issues would help to ensure that all topics relevant to tobacco use are covered.

LIMITATIONS OF THE SURVEY

The results of this survey must be viewed as essentially qualitative, partly due to the lack of control we had on who completed the survey and partly because the response rate from medical schools was only about a third. We chose to address all correspondence to the dean, using this as a generic term in the absence of any specific name or title accompanying the medical school address in the WHO directory, ${ }^{7}$ and assuming that schools would understand this to mean the most senior person in charge even though other titles might be used, such as president, head, or director. Survey instructions allowed the dean to nominate personnel most familiar with the curriculum and teaching about tobacco, and, consequently, respondents in a variety of positions completed the survey. Positions included dean and vice dean (or the equivalents), heads of departments, professors, and general teaching staff.

Although a response rate of $36 \%$ from all of the medical schools around the world is positive in the light of language barriers, postal problems, accuracy of existing databases on medical schools, and even war, we are, nonetheless, left with a subset of respondents on which to base our conclusions. We are pleased that a large percentage $(64 \%)$ of countries are represented by responses from at least one medical school, but recognise that the responding sample is tipped in favour of developed rather than developing countries, so response bias is possible. Of course, the most important bias in this study is that which would cause an overestimate or underestimate of the number of schools that teach about tobacco. Although it is possible that schools that have no teaching about tobacco may be less inclined to respond to the survey, our data suggest this may not be the case. The response rates from the different continents are fairly similar, ranging from $28 \%$ to $45 \%$, despite figures in table 1 which show marked differences between these regions regarding teaching about tobacco. For example, if such a bias were in effect, then Africa would be expected to show a much lower response rate than the North American or Australian/Pacific regions, but instead 36\% of medical schools in these regions responded.

An alternative explanation for the low response rate is that survey recipients were either too busy or unwilling to undertake the task of communicating with heads of departments and personnel involved in curriculum development to provide a response, particularly in medical schools where several departments take responsibility for covering tobacco issues, as was commonly reported in returned surveys. In addition, language could have been a significant barrier in many developing countries, where lack of ease with English or one of the four languages used in translated surveys, may have prevented the survey from connecting with the appropriate 
personnel. For example, two developing countries, the Philippines and China, showed very different response rates $(7 \%$ and $34 \%$, respectively), possibly due to the availability of the survey in Mandarin. Unfortunately, translations are costly and, therefore, necessarily restricted to a few major languages. Finally, a number of surveys were returned undelivered for a variety of reasons, including war and civil strife, such as in Yugoslavia.

However, all samples have inherent bias within them and the possibility still remains that our results are an overestimate of the percentage of medical schools that teach about tobacco, particularly among developing countries. Nevertheless, the sample provides a wide range of medical schools, small and large, from many different countries, developing and developed, and in a variety of circumstances. Further, the cumulative qualitative material regarding course objectives and content, barriers to teaching about tobacco, and suggested solutions, helps to highlight the many issues underlying the extent to which teaching about tobacco occurs.

COURSE OBJECTIVES AND CONTENT

Almost all respondents were concerned that the course impart knowledge about major tobacco-related diseases. Other issues were noted by a majority of respondents, such as the harmful components of tobacco smoke, impact on public health, effects of nicotine addiction, effects of passive smoking, and the doctor's role in smoking cessation and prevention. Interestingly, there is a discrepancy between reports in this current study that medical schools teach about tobacco-related diseases with those of previous studies which investigated medical students' knowledge of such diseases. ${ }^{1-412}$ The latter studies found that there was a general lack of knowledge among students about smoking as a major cause of important medical conditions including coronary artery disease, peripheral vascular disease, pulmonary emphysema, bladder cancer, and neonatal mortality, and in some countries, even lung cancer and chronic bronchitis. ${ }^{12}$ It is difficult to know the reasons for the disparity in the surveys. Possibilities are that medical schools may have increased their teaching of specific diseases recently in response to the results from these surveys, and that students may not be retaining or recalling the information provided because of work overload, lack of interest, or poor teaching.

Although some respondents report teaching about the important role the doctor can play in smoking cessation, only a third taught cessation techniques, with developing countries less likely than developed countries to teach such skills. This finding is consistent with that reported from previous surveys in which relatively few students accepted that it was the doctor's routine responsibility to advise patients on quitting if they did not have a smoking-related disease. ${ }^{12}$ In other words, students do not appear to have grasped the important responsibility that doctors have in disease prevention.
PROBLEMS

Respondents from developing countries commonly reported teaching about the role of their governments in encouraging or not encouraging foreign tobacco advertising and sponsorship, and in bringing in levies on tobacco products and legislation against smoking in public places. Some respondents commented on multinational tobacco companies that had entered their regions with the aim of increasing cigarette sales, including the establishment of cigarette factories. They reported on the various methods used by the tobacco industry to advertise and sponsor their products.

A difficult problem for medical schools in trying to include tobacco issues in the curriculum was overcoming a lack of motivation of staff and students, among whom smoking was common. In many countries smoking prevalence among doctors is higher or no different from that of the general population. ${ }^{13} 14$ Thus medical teachers are presenting smoking rather than non-smoking role models to students. To deal with the increasing problem of tobacco use globally, doctors need to be motivated to educate students about the social pressures exerted by smoking friends, family, and the mass media, and teach about the skills of intervention. However, this can only be achieved if they modify their own personal behaviour and present to students appropriate non-smoking attitudes and behaviour.

Respondents in developing countries commented on the lack of resources and training in the area of tobacco. One medical school in Africa raised the problem of scant or no figures for smoking rates in the general population available in their countries. Additionally, many low-income countries had more pressing acute diseases and natural disasters to deal with, such as tuberculosis, floods, and famines, before they believed that the topic of tobacco would be considered seriously.

In many developing countries, tobacco was an important cash crop and was strongly supported by their governments. Funds may not have been available to support teaching about tobacco in countries where there was a strong tobacco industry. This industry can produce pressure directly and indirectly on medical schools by affecting funding, and through advertising, affecting the attitudes of the community, medical school staff, and government. Where tobacco is a major source of revenue, government choices can be influenced.

\section{SOLUTIONS}

Improvements in administration methods were considered important by $42 \%$ of the medical schools that offered solutions. This included additional funding, revision of course content and teaching methods, and the need for integration and cooperation between various departments. Medical schools in developing countries wanted improved training for staff and resources so that appropriate teaching on tobacco could be delivered. Some respondents suggested "better international help and cooperation" in which 
selected staff were sent for training to a country that has a well-developed teaching course in tobacco. Others wanted international experts to visit them and train staff in medical schools throughout their country. Technology support is clearly an area that requires development. It was encouraging that almost all of the medical schools expressed interest in receiving a copy of the book Educating medical students about tobacco: planning and implementation, ${ }^{11}$ which is being supplied to medical schools and includes sections covering tobacco-related diseases and cessation methods for doctors to use.

Respondents in developing countries also wanted effective means of disseminating information to the population. More "intense anti-smoking propaganda" was needed. A quarter of respondents complained of poor communication, conflicting interests, and the need for improvements and changes in staff and community attitudes. Respondents said that government legislation and attitudes needed to change if progress was to be made. There was particular emphasis given to legislation to control tobacco advertising and changing crops from tobacco cultivation.

In conclusion, the Tobacco Prevention Section of the IUATLD continues to contribute to tobacco control objectives by stimulating interest in teaching about tobacco in medical schools through its series of studies conducted among medical students and in medical schools. In addition, invitations have been extended to international experts to train staff of medical schools and to provide teaching resources on tobacco. Cooperation among countries is imperative to overcome the problem of tobacco-related diseases. Indeed there is no area of medical education and preventive medicine in which emphasis will yield greater returns in better health, saved lives, and reduced medical costs than the prevention and cessation of smoking. ${ }^{15}$
This survey was funded by the Tobacco Prevention Section of the International Union Against Tuberculosis and Lung Disease; and the National Drug and Alcohol Research Centre, University of New South Wales.

1 Tessier JF, Freour PP, Crofton J, et al. Smoking habits and attitudes of medical students towards smoking and anti-smoking campaigns in fou
Eur f Epidemiol 1989;5:311-21.

2 Tessier JF, Freour PP, Nejjari C, et al. Smoking behaviour and attitudes of medical students towards smoking and anti-smoking campaigns: a survey in 10 African and Middle Eastern countries. Tobacco Control 1992;1:95-101.

3 Tessier JF, Freour PP, Belougne D, et al. Smoking habits and attitudes of medical students towards smoking and
anti-smoking campaigns in nine Asian countries. Int 7 Ep $i-$ anti-smoking campaigns

4 Tessier JF, Freour PP, Nejiari C, et al. Smoking behaviour and attitudes towards smoking of medical students in Australia, Japan, USA, Russia, and Estonia. Tobacco Control 1993;2:24-9.

5 Canton JC, Baker LC, Hughes RG. Preparedness for practice: young physicians' views of their professional education. FAMA 1993;270:1035-40.

6 Peto R, Lopez AD. Worldwide mortality from current smoking patterns: WHO consultative group on statistical aspects of tobacco related mortality. In: Dunston B, Jamrozik K, eds.Tobacco and health 1990 - the global war. Proceedings of the seventh world conference on tobacco and health, 1-5 April 1990. Perth: Health Department of Western Australia, 1990.

7 World Health Organisation. World directory of medical schools, 6th ed. Geneva: WHO, 1988

8 Richmond R, Larcos D, Debono D. A worldwide survey of teaching about tobacco in medical schools. In: Richmond R, ed. Educating medical students about tobacco: planning and implementation. Paris: International Union Against Tuberculosis and Lung Disease, 1997:281-98.

9 United Nations. Human development report. New York: Oxford University Press, 1995.

10 United Nations. State of the world population. New York: United Nations Population Fund, 1995.

11 Richmond R, ed. Educating medical students about tobacco: planning and implementation. Paris: International Union Against Tuberculosis and Lung Disease, 1997.

12 Crofton JW, Freour PP, Tessier JF. Medical education on tobacco: implications of a worldwide survey. Med Educ 1994;28:187-96.

13 Kocabaş A, Burgut R, Bozdemir N, et al. Smoking patterns at different medical schools in Turkey. Tobacco Control 1994;3:228-35.

14 Masironi R. Doctors as non-smoking exemplars. In: Richmond R, ed. Educating medical students about tobacco: Rlanning and implementation. Paris: International Union planning and implementation. Paris: Internation

15 Pollin W. Foreword. In: Jarvik ME, Cullen JW, Gritz ER, et al, eds. Research on smoking behavior. Washington, DC: National Institute on Drug Abuse, 1977. (NIDA research monograph 17, US Government Printing Office.) 